\title{
Does Pan Diameter Influence Carbon Monoxide Levels During Heating of Water to Boiling Point With a Camping Stove?
}

\author{
Simon Leigh-Smith, MBChB, MRCGP, FRCSEd (A\&E); Richard Stevenson, MB, ChB, BMSc, Hons MRCP; \\ Martin Watt, MB, ChB, FRCS, FFAEM, DipFM; Ian Watt; Angus McFadyen, BSc, MSc, DipSAD, Cmath, \\ MIMA, FSS; Stan Grant, PhD, MSc, BEd, DPE \\ From the Defence Medical Services, UK (Dr Leigh-Smith); Monklands Hospital, University of Glasgow, Glasgow, Scotland (Dr Stevenson \\ and $\mathrm{Mr}$ M. Watt); the Institute of Biomedical and Life Sciences, University of Glasgow, Glasgow, Scotland (Mr I. Watt and Dr Grant); and \\ Glasgow Caledonian University, Glasgow, Scotland (Mr McFadyen).
}

\begin{abstract}
Objectives.-To determine whether pan diameter influences carbon monoxide (CO) concentration during heating of water to boiling point with a camping stove. The hypothesis was that increasing pan diameter increases $\mathrm{CO}$ concentration because of greater flame dispersal and a larger flame.

Method.- - This was a randomized, prospective study. A Coleman Dual Fuel 533 stove was used to heat pans of water to boiling point, with $\mathrm{CO}$ concentration monitored every 30 seconds for 5 minutes. The stove was inside a partially ventilated $200-\mathrm{L}$ cardboard box model that was inside an environmental chamber at $-6^{\circ} \mathrm{C}$. Water temperature, water volume, and flame characteristics were all standardized. Ten trials were performed for each of 2 pan diameters (base diameters of $165 \mathrm{~mm}$ [small] and $220 \mathrm{~mm}$ [large]).

Results. - There was a significant difference $(P=.002)$ between the pans for $\mathrm{CO}$ levels at each measurement interval from 60 seconds onward. These differences were markedly larger after 90 seconds, with a mean difference of $185 \mathrm{ppm}(95 \%$ CI 115, $276 \mathrm{ppm})$ for all the results from 120 seconds onwards.

Conclusion.- - This study has shown that there is significantly higher CO production with a largediameter pan compared with a small-diameter pan. These findings were evident by using a camping stove to heat water to boiling point when a maximum blue flame was present throughout. Thus, in enclosed environments it is recommended that small-diameter pans be used in an attempt to prevent high CO levels.
\end{abstract}

Key words: carbon monoxide, stove, camp, poisoning

\section{Introduction}

Carbon monoxide (CO) poisoning in tents is an important issue with many accounts of both nonfatal and fatal occurrences. $^{1}$ Although cooking has been associated with high $\mathrm{CO}$ production (D. Smith, unpublished data), ${ }^{2-5}$ there is no consensus on the possible causes of high CO levels while cooking. Previous studies concluded that $\mathrm{CO}$ production is lowest with a freely burn-

Corresponding author: Simon Leigh-Smith, Institute of Naval Medicine, Monckton House, Alverstoke, Gosport, Hants, PO12 2DL, UK (e-mail:simonlsuk@aol.com). ing flame and increased with pan contact with the flame while cooking or melting snow and ice (D. Smith, unpublished data). ${ }^{6-9}$ This led to the theory that higher $\mathrm{CO}$ concentration with cooking is a result of flame cooling, with elevated levels of incomplete combustion (D. Smith, unpublished data). ${ }^{3,7}$ However, a recent study in this laboratory showed no significant difference in $\mathrm{CO}$ production between a pan of ice and a pan of water when each was heated to boiling point while the stove burnt with a maximum blue flame. ${ }^{10}$ This finding and the knowledge that not only pans but stones ${ }^{7}$ and aluminium blocks $^{8}$ increase $\mathrm{CO}$ production from stoves led to the 
hypothesis that pan diameter may influence $\mathrm{CO}$ production from camping stoves. There appear to be no previous controlled trials investigating the effect of pan diameter on $\mathrm{CO}$ production, but reference to increased $\mathrm{CO}$ production with larger-diameter pans exists (D. Smith, unpublished data). We were unable to obtain the original reference to this (which is a thesis for a Masters of Medical Science), but the original citation is included here for completeness. ${ }^{3}$

The aim of this study was to compare CO concentration during heating of water to boiling point with a camping stove in 2 different-diameter pans.

\section{Methods}

This was a randomized, prospective study performed at sea level. We tested the null hypothesis that there is no difference in $\mathrm{CO}$ production among different-diameter pans when bringing each to boiling point on a camping stove under standardized conditions.

A $200-\mathrm{L}(100 \times 45 \times 45 \mathrm{~cm}), 1-\mathrm{cm}$ thick cardboard box that had a $900-\mathrm{cm}^{2}(20 \mathrm{~cm}$ high $\times 45-\mathrm{cm}$ wide $)$ area of ventilation on 1 side at floor level was used. The box was placed on end inside the cold chamber, maintained at $-6^{\circ} \mathrm{C} \pm 2^{\circ} \mathrm{C}$. This partially ventilated box model allows indefinite burning of a camping stove because it avoids the problems of hypoxic self-extinction that occur in nonventilated models (D. Smith, unpublished data). ${ }^{5,7,9}$ It results in consistent $\mathrm{CO}$ responses to the same conditions and allows comparisons of $\mathrm{CO}$ production when a variable is altered. ${ }^{9}$

The stove was positioned in the center underneath this box. Aluminum pans were used with a base diameter of $165 \mathrm{~mm}$ (small) and $220 \mathrm{~mm}$ (large). Each was filled with $500 \mathrm{~mL}$ of water with a starting temperature of $5^{\circ} \mathrm{C}$ $\pm-2^{\circ} \mathrm{C}$.

The remote sensor of a Neotronics CO101 probe ${ }^{10}$ penetrated the top of the box to a depth of $5 \mathrm{~cm}(82 \mathrm{~cm}$ above flame height). This gave continuous $\mathrm{CO}$ concentration readouts at the top of the cardboard box, up to a concentration of $4000 \mathrm{ppm}$. Carbon monoxide concentration monitoring was performed outside the chamber with a remote monitor and extended sensor placed through a $10-\mathrm{cm}$ diameter hole in the chamber wall. Before each trial, the 200-L box and environmental chamber were ventilated to $0 \mathrm{ppm} \mathrm{CO}$ concentration. Visual monitoring of the stove and flame was performed at the start and end of each trial.

For unavoidable reasons, the Coleman Peak stove used in the previous study ${ }^{9}$ could not be used here, and a Coleman Dual Fuel 533 stove was used instead. This is an almost identical multi-fuel pressure stove, although the change may affect direct comparisons of actual $\mathrm{CO}$ concentration between the 2 studies. For each trial the stove was refilled with Coleman fuel and had a standardized priming sequence: 30 pumps, light, 30 pumps, set control lever to maximum, burn for 5 minutes, 30 pumps. This procedure was carried out to preheat the stove and standardize the flame characteristics to "maximum" blue before commencing the trial. Although a low flame produces the highest CO concentration, ${ }^{3}$ a maximum blue flame was adopted for this experiment because it would usually set the conditions for bringing water to boiling point and is more standardized than a low flame setting. The flame was observed to be maximum blue at the start and finish of each trial and was assumed to be present for the intervening 5 minutes. This assumption was based on previous findings that any significant yellow change in the flame was associated with a rapid rise to extremely high $\mathrm{CO}$ concentration, fuel leaking from the stove jets, and the stove becoming depressurized. ${ }^{9}$ If this had occurred, a blue flame would not have been found at the end of each trial, as was the case here.

Monitoring time started for each trial when the pan was placed onto the stove. Ten trials for each pan diameter were run in random order, and $\mathrm{CO}$ concentration was monitored every 30 seconds for 5 minutes. A diagram of this setup is included in the previous study. ${ }^{9}$

\section{STATISTICAL ANALYSIS}

Results were analyzed by the Minitab statistical package. ${ }^{11}$ A 2-way analysis of variance was initially performed to determine that differences existed between the groups. Data were then assessed for normal distribution by the Anderson-Darling normality test, after which either an unpaired Student's $t$ test or a Mann-Whitney $U$ test was used to compare the results of the 2 variable conditions.

\section{Results}

The Figure shows the means of the 10 large-pan diameter trials and 10 small-pan diameter trials and clearly gives the impression of increased $\mathrm{CO}$ production with the larger pan. The mean CO concentration of the large pan peaked at $780 \mathrm{ppm}$ (SD 90), whereas the small pan peaked at $570 \mathrm{ppm}$ (SD 107).

The 30- and 60-second measurements were not normally distributed. A Mann-Whitney $U$ test showed no significant difference at 30 seconds $(P=.158)$ but a significant difference at 60 seconds $(P=.002)$. The measurements from 90 seconds onward were normally distributed $(\alpha=.05)$, so an unpaired Student's $t$ test was used for analysis. There was a significant difference $(P$ 


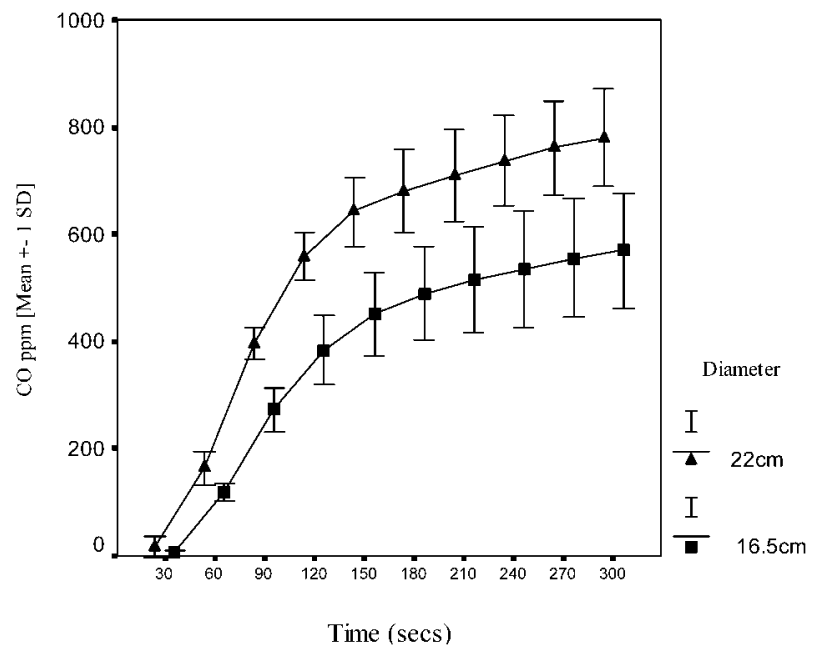

Carbon monoxide measurements for small- and large-diameter pans.

$<.001)$ for every set of measurements from 90 to 300 seconds. The large pan had a significantly higher CO concentration at each of the time points from 60 seconds onward. The Table shows the $95 \%$ CIs for these differences. These were markedly larger after 90 seconds, with a mean difference of $185 \mathrm{ppm}$ (95\% CI 115, 276 ppm) for all the results from 120 seconds onward.

\section{Discussion}

A statistical and perhaps clinically significant difference in $\mathrm{CO}$ production has been demonstrated when pans of different diameters are used to boil water. These findings were evident with a Coleman Dual Fuel 533 stove to heat water to boiling point with a maximum blue flame.

The increased CO concentration with cooking has previously been attributed to flame cooling, and it has been suggested that the larger the pan the greater the cooling effect. ${ }^{3,6}$ Our previous study showed no difference in $\mathrm{CO}$ production when heating pans of ice or water ${ }^{9}$ and, combined with the findings of this study, leads us to speculate that flame dispersal rather than flame cooling causes increased CO production. It is further postulated that this larger flame leads to an increase in the absolute level of combustion (with more production of both $\mathrm{CO}$ and carbon dioxide) rather than the percentage of incomplete combustion (with an increased proportion of $\mathrm{CO}$ ), as has been postulated for the flame-cooling theory (D. Smith, unpublished data). 3,6 These hypotheses would explain the elevated $\mathrm{CO}$ levels with increasing pan diameter, as well as the proportionally larger increase seen when a freely burning stove has a pan or any other ob-
95\% CI for difference in carbon monoxide concentration in parts per million between large and small pans

\begin{tabular}{rr}
\hline Time $(s)$ & $95 \% C I$ \\
\hline 90 & 90,158 \\
120 & 122,228 \\
150 & 122,258 \\
180 & 114,270 \\
210 & 108,281 \\
240 & 109,294 \\
270 & 111,300 \\
300 & 117,304 \\
\hline
\end{tabular}

ject placed onto the flame, and are discussed in more detail in the subsequent review article. ${ }^{1}$

The experimental conditions used in this study (ie, partially ventilated box model) have resulted in consistently different $\mathrm{CO}$ concentration between 2 conditions. This finding further validates the model devised previously in this laboratory. ${ }^{9}$ It is inappropriate to make a direct comparison of $\mathrm{CO}$ concentrations between this study and a recent study carried out in this laboratory ${ }^{9}$ because the stoves were different and the absolute $\mathrm{CO}$ levels found are applicable to this stove alone.

\section{Conclusions}

This study has shown that there is significantly higher $\mathrm{CO}$ production with a large-diameter pan compared with a small-diameter pan. These findings were evident with a camping stove used to heat water to boiling point when a maximum blue flame was present throughout. This increase has the potential to enhance the risk of $\mathrm{CO}$ poisoning to tent occupants. Thus, in enclosed environments it is recommended that small-diameter pans be used in an attempt to prevent high CO levels. The safest small-diameter pan should be used in tents, bearing in mind the added potential risks of instability with a taller but smaller-diameter pan. Relating the CO levels found in this study to the actual clinical risk within a tent is difficult, and a more complete discussion on the risks of $\mathrm{CO}$ poisoning in tents is recommended in the "References" section. ${ }^{1}$

\section{References}

1. Leigh-Smith S. Carbon monoxide poisoning in tents-a review. Wilderness Environ Med. 2004;15:157-163.

2. Keyes LE, Hamilton RS, Rose JS. Carbon monoxide exposure from cooking in snow caves at high altitude. Wilderness Environ Med. 2001;12:208-12. 
3. Harrigan M. A Study of Carbon Monoxide Exposure Amongst Troops During Arctic Training [Master's thesis], 1992.

4. Turner WA, Cohen MA, Moore S, et al. Carbon monoxide exposure in mountaineers on Denali. Alaska Med. 1988; 30:85-90.

5. Pugh L. Carbon monoxide hazard in Antarctica. BMJ. 1959;34(5116):192-196.

6. Henderson Y, Turner J. Carbon monoxide as a hazard of polar exploration. Nature 1940;145:92-95.

7. Westerlung K, von Ubisch $\mathrm{H}$. Carbon monoxide from small camping appliances and from stoves without chimney connection. Nordisk Hygienisk Tidskrift. 1972;53:26-33.
8. Prescher KE. Occurrence of carbon monoxide, carbon dioxide and nitrogen oxides during the use of gas stoves [in German]. Schriftenr Ver Wasser Boden Lufthyg. 1982;53: 191-198.

9. Leigh-Smith S, Watt I, McFadyen A, et al. Comparison of carbon monoxide levels during heating of ice and water to boiling point with a camping stove. Wilderness Environ Med. 2004;15:164-170.

10. Neotronics. Neotronics Ltd, Hatchpond House, Nuffield Industrial Estate, Poole, BH17 0RZ, Dorset, UK.

11. Statistical Software [computer program].Version 13.32. State College, PA: 2003. 